\title{
SOLIDIFICATIION MODELING OF ALLOY 718 STRUCTURAL CASTINGS
}

\author{
K. O. Yu*, J. J. Nicholas** and L. Hosamani*** \\ * PCC Airfoils, Inc., Beachwood, OH; now with Concurrent \\ Technologies Corporation, Johnstown, PA \\ ** PCC Airfoils, Inc., Beachwood, $\mathrm{OH}$ \\ *** Precision Castparts Corporation, Portland, OR
}

\begin{abstract}
Efforts were undertaken jointly between PCC Airfoils and PCC Structurals Division to simulate solidification conditions and predict the occurrence of shrinkage and microporosity defects in Alloy 718 structural castings. The approach used finite element thermal analysis validated by experiments. An engine rail was selected as the demonstration part. A finite element thermal model was used to generate data on solidification conditions (i.e., solidification sequence, isochron, temperature gradient (G) and solidification rate $(\mathrm{R})$ ). A baseline condition was first established by matching model-predicted shrinkage locations with known inspection results for actual gating and casting conditions. A second model was then built for a casting with a different gating system to predict shrinkage locations prior to inspection. It was found that the shrinkage locations predicted by the second model match rcasonably wcll with casting inspection results.
\end{abstract}




\section{$\underline{\text { Introduction }}$}

Since its first use in structural castings back in 1964, cast Alloy 718 has become the predominant material for large aircraft engine structures: approximately $75 \%$ of the structural castings in today's aircraft engines are produced in Alloy 718. The size and complexity of today's large structural casting have more than doubled since the 1960's and the quality requirements have steadily increased. In order to comply with these requirements, the casting process must be under stringent control, with optimized gating systems, in order to ensure sound castings. The integrity of castings depends upon their microstructure (e.g., grain size) as well as the amount of defects (e.g., hot tearing, shrinkage and microporosity), which are determined by casting solidification conditions.

The investment casting process is complex because it involves many physical phenomena such as heat transfer, fluid flow, thermal stress, microstructure evolution, and defect formation. The thermal history of a casting is the main driving force for the evolution of microstructures and defects and the development of stresses. Finite element modeling has been used to gain an understanding of the thermal history and to predict casting microstructures and defects of investment cast turbine airfoils and castings made by other casting processes (1-7). The purpose of this paper is to demonstrate the application capability for finite element modeling of investment cast complex shaped superalloy structural castings.

\section{Approach}

The approach used finite element thermal analysis validated by experiments. An engine rail was selected as the demonstration part. A finite element model was used to generate data on solidification conditions (i.e., solidification sequence, isochron, temperature gradient $(\mathrm{G})$ and solidification rate $(\mathrm{R})$ ) and to predict macroshrinkage and microporosity. A baseline condition was first established by matching model-predicted shrinkage locations with known x-ray inspection results for actual gating and casting conditions. A second model was then built for a casting with a different gating system to predict shrinkage locations prior to $\mathrm{x}$-ray inspection. If the predicted shrinkage locations of the second model match casting inspection results, we can then conclude that finite element thermal modeling is an effective tool for predicting shrinkage defects in geometrically complex structural castings.

\section{Experimental Procedure}

Two molds ( 4 parts per mold) of an engine rail were cast. The details of the part geometry are shown in Figure 1. Note that one of the blind risers was cut off during post casting processing. For mold one, two parts had blind risers at the two ends of the part (Figure 1), and two other parts had no blinder risers. All parts had no blinder risers for mold two. Another difference between these two molds was the ingate location. For mold one, there were two ingates per part and each ingate was located between the two lugs. On the other hand, there was only one ingate per part for mold two and it was located at the center portion of the bracket. Both molds were assembled in the same manner. Figure 2 shows the assembled wax pattern for mold two.

The metal pouring and mold preheat temperatures for both molds were $1538^{\circ} \mathrm{C}$ $\left(2800^{\circ} \mathrm{F}\right)$ and $982^{\circ} \mathrm{C}\left(1800^{\circ} \mathrm{F}\right)$, respectively. After shake out of the mold, all castings were sand blasted and macroetched to show grain structure. X-ray inspections were also used to check the shrinkage locations. 


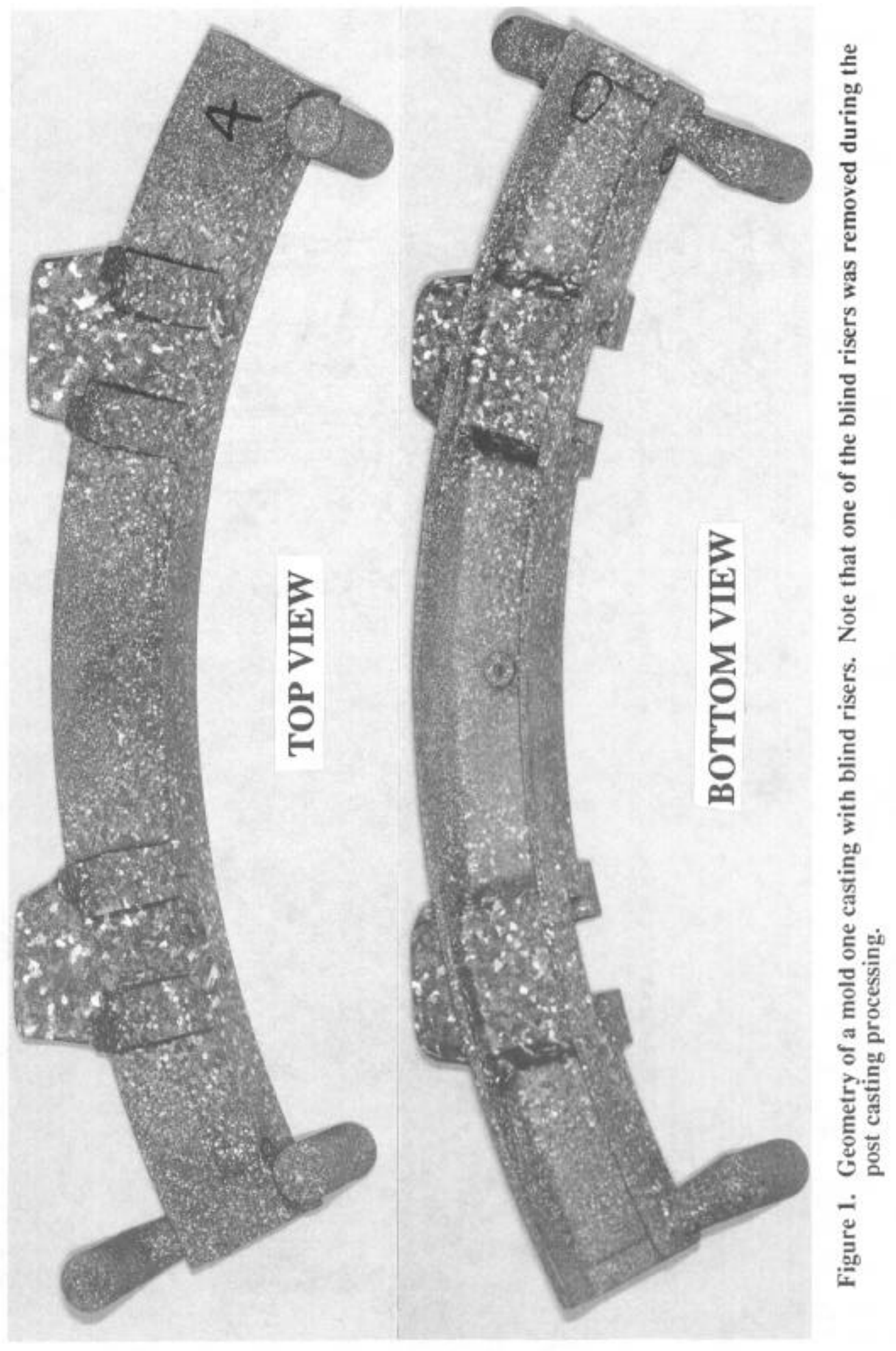



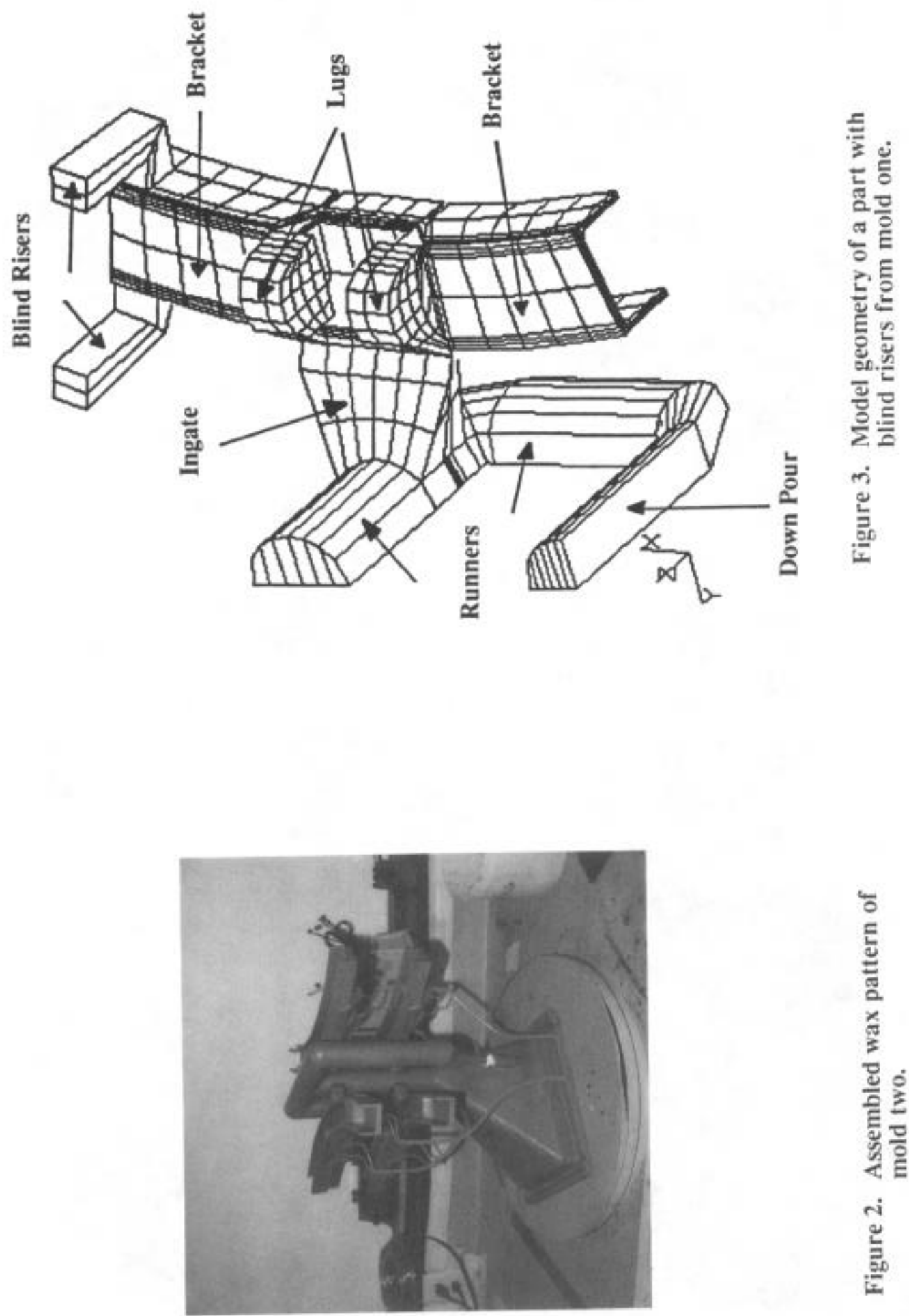

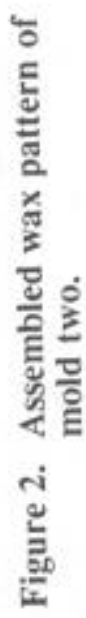




\section{Finite Element Models}

The model geometry of a part with blind risers from mold one is shown in Figure 3. Due to the symmetry, only one half of the part was modeled. This model was used to establish the baseline condition. The model geometry for mold two is shown in Figure 4. For convenience, rectangular instead of circular cross-sections were used for the blind risers of mold one and the down-pour and blind runners of mold two. These models were built and meshed in a commercial finite element software package PATRAN. The heat transfer solution was performed with another commercial finite element software ANSYS. After simulation was completed, the casting temperature history data were transferred from ANSYS back to PATRAN and post-processing was then performed in PATRAN again.

\section{Establishing Baseline Condition}

\section{$\underline{\text { Inspection Results of Mold One }}$}

Figure 5 shows the inspected shrinkage location for the castings of mold one. Two parts with blind risers show shrinkage near the roots of the blind risers (location A). One of the two parts without blind risers has microporosity in the center of the horizontal plate of the bracket (location B). The casting grain size distribution of a part with blind risers is shown in Figure 6.

\section{Simulation Results of Mold One}

A two-dimensional heat transfer model with a pre-assumed mold filling patten was used to calculate the molten metal initial temperature. The calculated initial metal temperature distribution after the pour is shown in Figure 7. It can be seen that blind risers, which have the lowest initial temperature, are predicted to decrease in temperature about $133^{\circ} \mathrm{C}\left(240^{\circ} \mathrm{F}\right)$ during the pour. The accuracy of this calculation can be verified by comparing the calculated initial metal temperature to casting grain size distribution shown in Figure 6. The lower the initial metal temperature, the faster the metal cooling rate and the finer the grain size. From Figure 7 it can be predicted that blind risers should have the finest grain size; the ingate (which has the highest initial metal temperature) should have the largest grain size; and the lugs should have the grain size between that of ingate and blind risers. These predictions are consistent with the grain size distribution shown in Figure 6.

There are two types of shrinkage: macroshrinkage and microporosity. Macroshrinkage is controlled by the casting bulk heat transfer condition. If there is an isolated region in the casting that is last to solidify, macroshrinkage forms in that region. An isochron is a contour plot that illustrates regions of constant time for castings to cool to a specified temperature or fraction of solid. If the specified temperature for the isochron plot is the alloy solidus temperature (i.e., $100 \%$ solid), then an isolated spot with a higher cooling time represents the region last to solidify. This is where macroshrinkage is expected to form. Figure 8 shows an isochron (time to reach $35 \%$ fraction of solid) plot. Note that one blind riser has been taken out so the isolated dark area (representing long isochron time) near the root of the blind riser (location A) is more visible. It can be seen that the roots of blind risers and lugs are the last two regions to solidify and, hence, can potentially form shrinkage. For lugs, since the runner and ingate have an even larger isochron value and can readily feed the lugs, we would not expect to see shrinkage in the lugs. On the other hand, areas near location A need feeding from blind risers to avoid the formation of shrinkage. However, blind risers have about the same isochron value as the root regions; thus it is very difficult for areas near location A to have good feeding from blind risers. Consequently, there is a good possibility for forming shrinkage in those areas. This conclusion is consistent with part inspection results shown in Figure 5. 

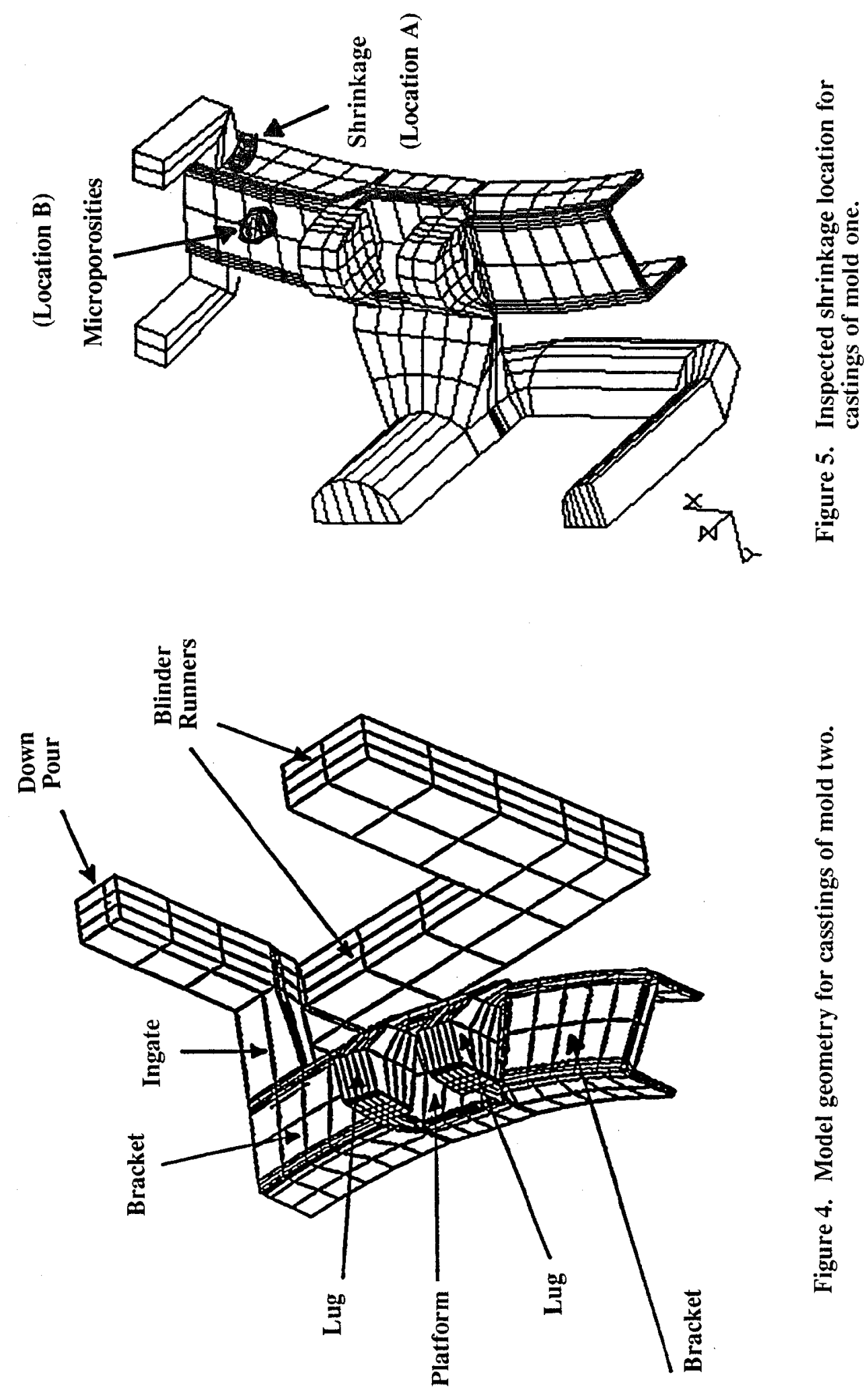

 


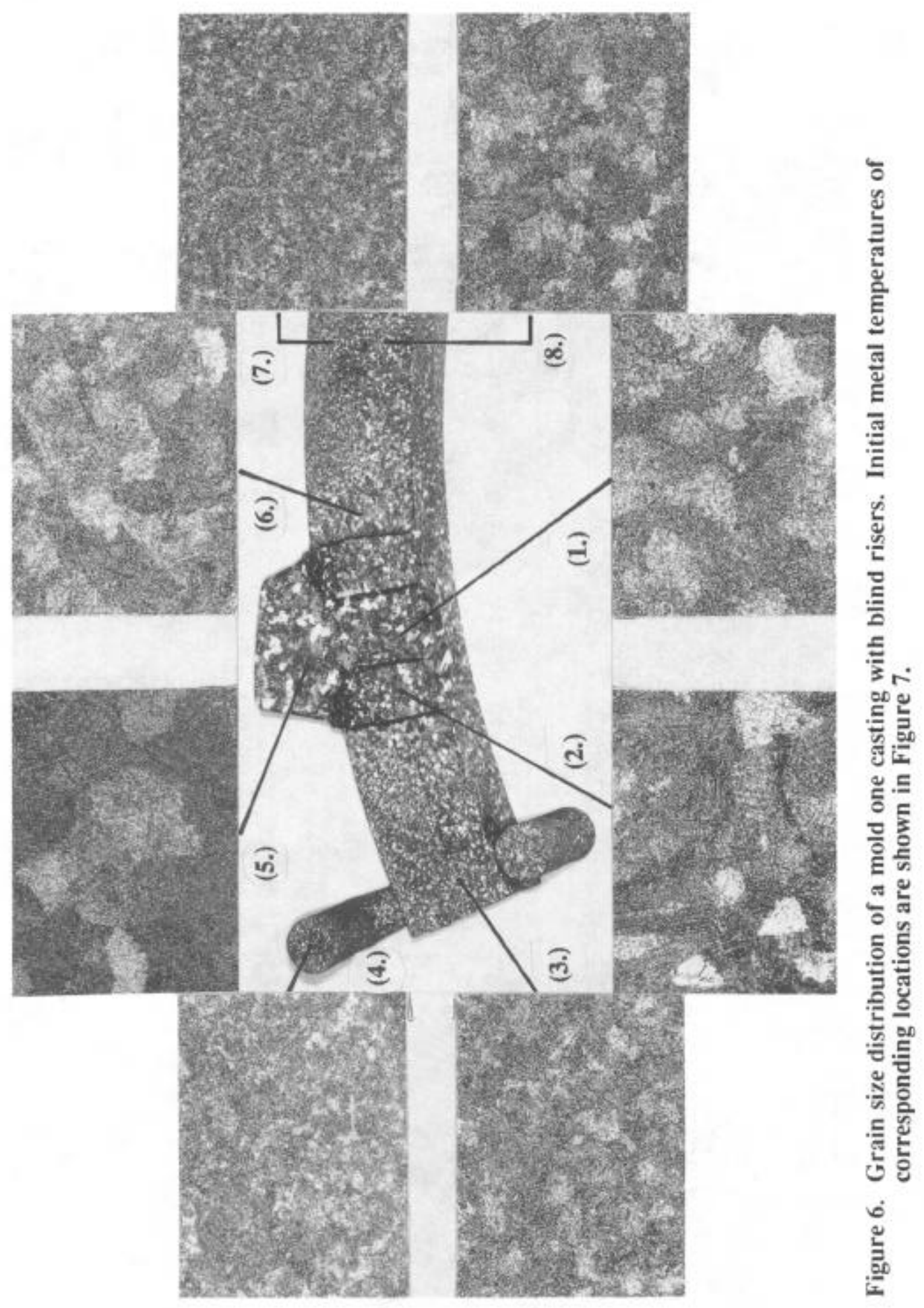



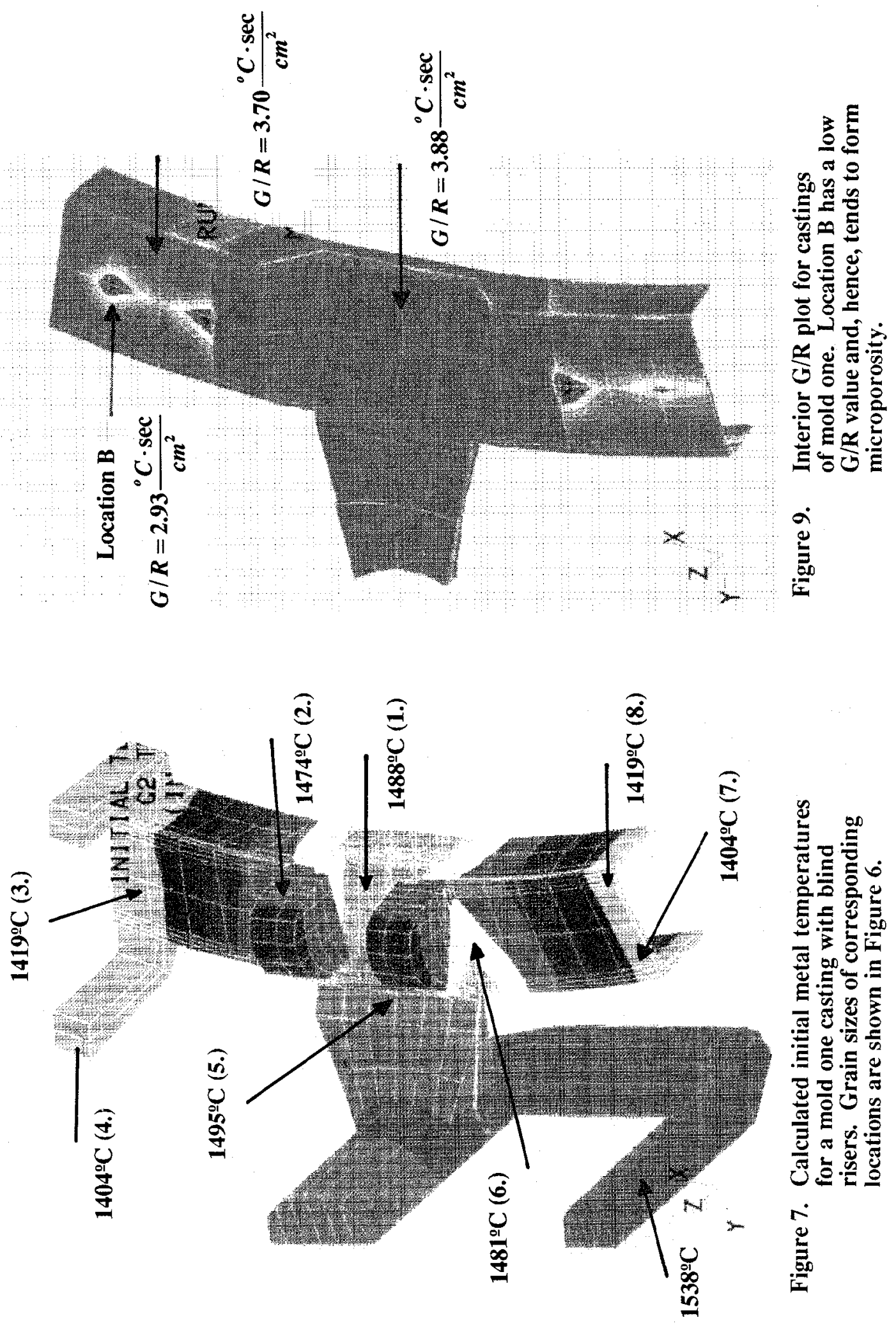


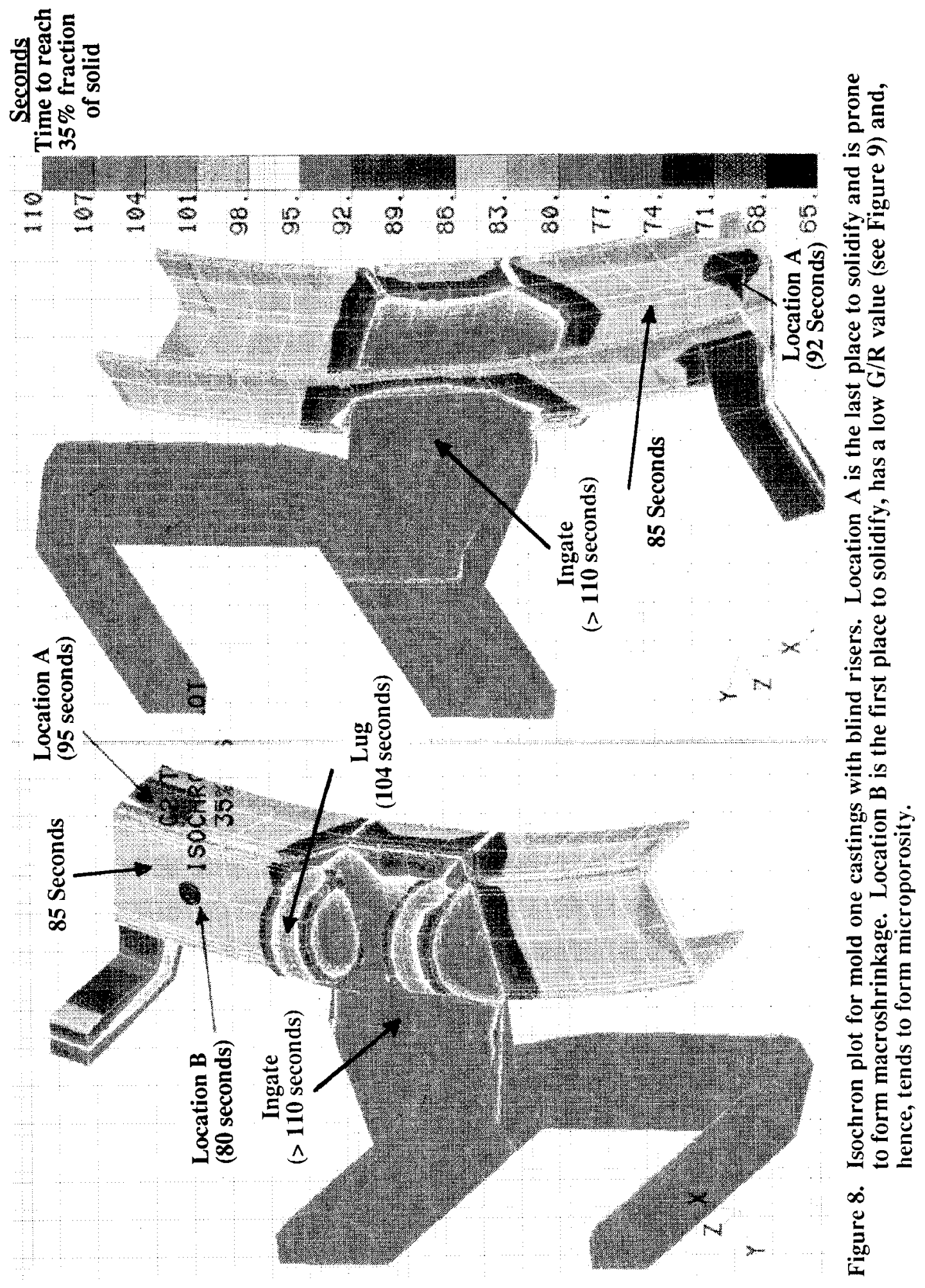


Microporosity forms near the end of solidification in the interdendritic regions ( 8 , 9). It is controlled by the $G / R$ ratio ( $G$ is the temperature gradient and $R$ is the solidification rate) at a specific temperature $(3,4,6)$. The lower the $G / R$ ratio, the higher the tendency that microporosity will form. Figure 8 shows that because center portions of the horizontal plate of the bracket (location B) cool faster than the surrounding areas, they have a lower isochron value. Since solidification fronts of location B move toward all surrounding areas simultaneously, the temperature gradients in location B are low and solidification rates are high, i.e., low G/R values in location $B$. Thus, we may see some microporosity in that area. Figure 9 shows a G/R plot of the interior portion of the casting. It indicates that interior microporosity may be formed in areas with dark colors (including location B). This prediction is consistent with the result of Figure 8. Note that the microporosity in location $B$ is the result of low $G / R$ value in the area which is the first to solidify whereas shrinkage in areas near roots of blind risers (location A) are results from isolated spots which are last to solidify. Thus, the severity of microporosity in location $B$ is less intensive than that of shrinkage in location A. Consequently, microporosity in location B may not be seen in X-ray inspection. This conclusion explains why only one $\mathrm{x}$-ray indication was found in location $\mathrm{B}$ for all four castings.

\section{Modeling and Inspection Results of Mold Two}

Figure 10 is an isochron (time to reach $35 \%$ fraction of solid) plot indicating that the lower portions of the lugs, (Locations A and B) and the platform between them (Location C), are isolated areas that are last to solidify. Hence, these areas are prone to form shrinkage. Furthermore, Figure 10 shows that Location $D$ (which is close to the gate and underneath Location $\mathrm{A}$ ) has shrinkage, whereas Location $\mathrm{E}$ (which sits on the similar location of Location D but is underneath Location B) does not have shrinkage. The comparison of modcl-predicted shrinkage and microporosity locations (left side of the gate) with casting inspection results (right side of the gate) are shown in Figure 11. It can be seen that the model-predicted shrinkage locations, in general, match the inspection results.

\section{Conclusions}

Finite element thermal modeling has been applied to predict shrinkage formation in investment cast Alloy 718 engine structural castings. Model predictions, in general, agree with casting inspection results. Furthermore, model predicted initial metal temperature distribution is consistent with indications from casting grain size distribution.

\section{References}

1. M. J. Beffel, J. O. Wilkes, and R. D. Pehlke, "Finite Elcment Simulation of Casting Processes," AFS Trans., 94 (1986), pp. 757-764.

2. M. J. Beffel, K. O. Yu, M. Robinson and K. R. Schneider, "Computer Simulation of Investment Casting Processes," JOM, 41 (2) (1989), pp. 27-30.

3. K. O. Yu, M. J. Beffel, M. Robinson, D. D. Goettsch, B. G. Thomas, D. Pinella and R. G. Carlson, "Solidification Modeling of Single Crystal Investment Castings," AFS Trans. (1990), pp. 417-428.

4. K. O. Yu, J. J. Nichols and M. Robinson, "Finite Element thermal Modeling of Casting Microstructures and Defects," JOM, 44 (6) (1992), pp. 21-25.

5. J. S. Tu and K. K. Foran, "The Application of Defect Maps in the Process Modeling of Single-Crystal Investment Casting," JOM, 44 (6) (1992), pp. 26-28.

6. K. O. Yu, J. A. Oti, M. Robinson and R. G. Carlson, "Solidification Modeling of Complex-Shaped Single Crystal Turbine Airfoils," Superalloys 1992, TMS, 1992, pp. $135-144$.

7. K. O. Yu, J. A. Oti and W. S. Walston, "Solidification Modeling of NiAl Single Crystal Castings," Mat. Res. Soc. Symp. Proc., Vol. 288, 1993. pp. 915-920. 

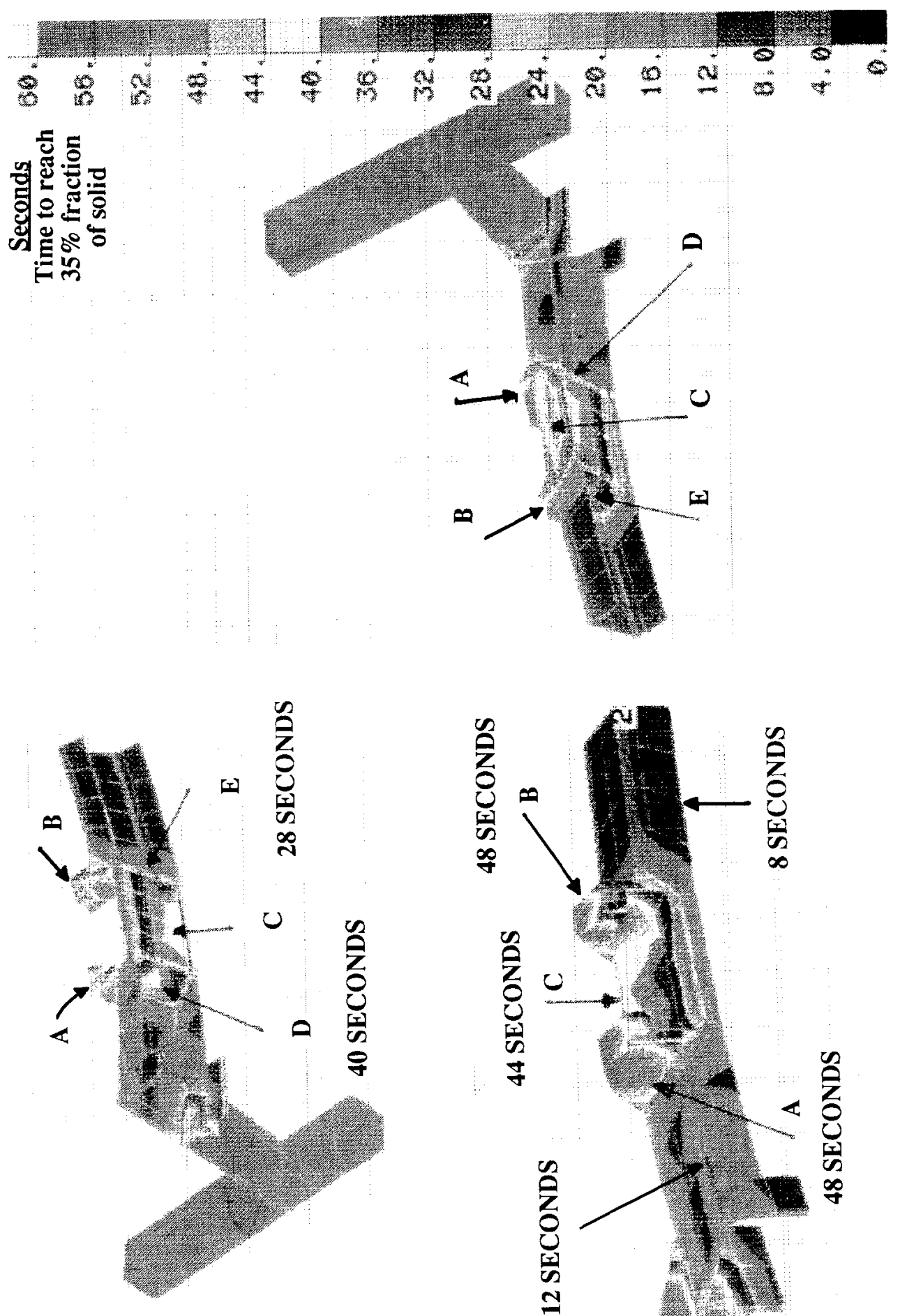

$\sum_{\substack{0 \\ \infty}}^{\infty}$

हี

这总

‥

焉

的

ส

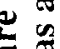

(

要

흠

흔

.

일

을

는

을

氙

․ㅗ

E.

등 꼻

층

50

昰

탱ㅇㅇㅇ

응

흠홍

흔

递

$\underset{ }{\stackrel{0}{0}}$ 
8. E. Niyama et al. "CIATF," paper no. 10 (1982).

9. J. Lecompte-Beckers, "Study of Microporosity Formation in Nickel-Base Superalloys," Met. Trans. A., 19A (September, 1988), pp. 2341-2348.
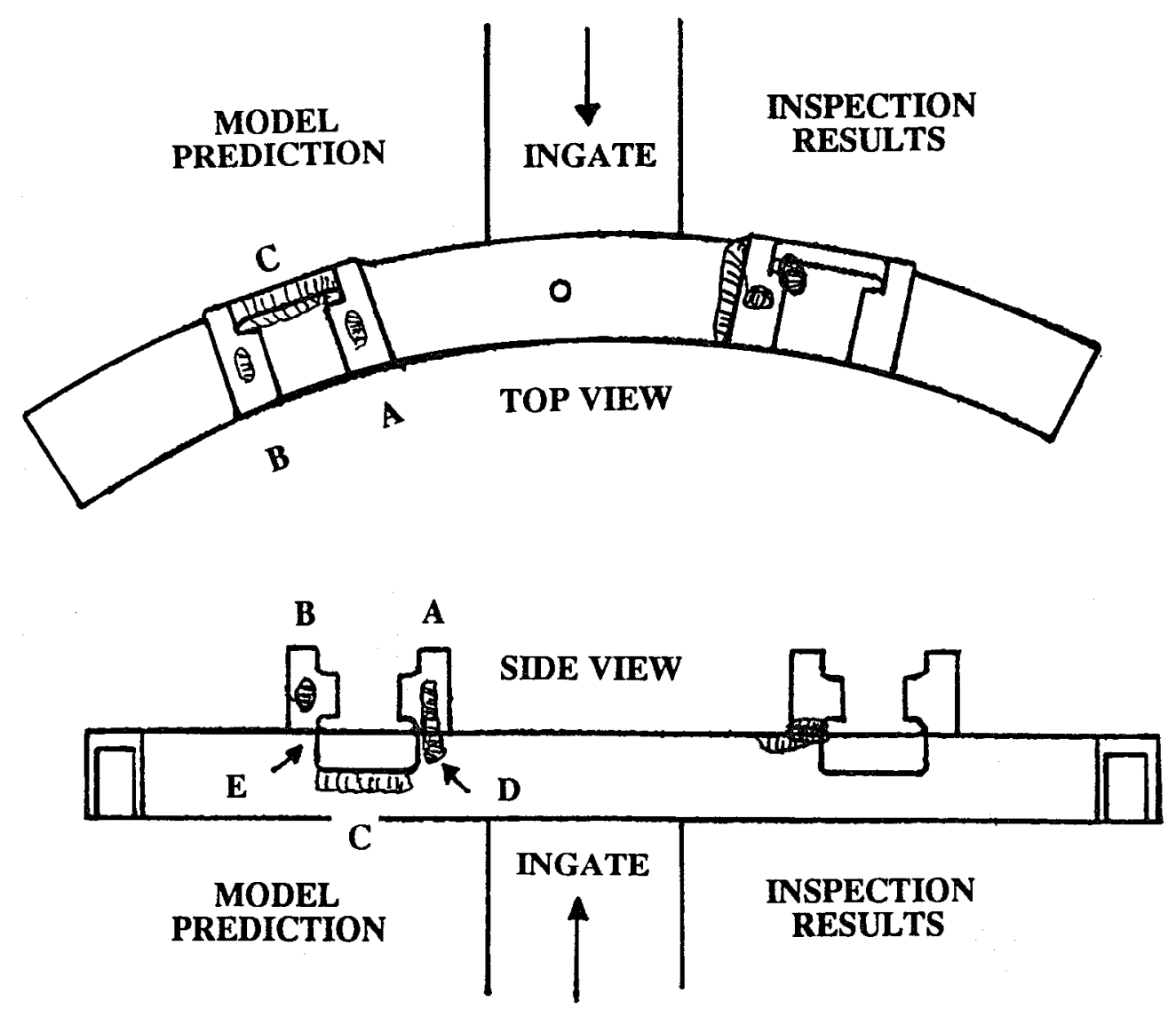

Figure 11. Comparison of model predicted shrinkage locations (left side of the gate) with inspection results (right side of the gate) for castings of mold two. 